\title{
TENDÊNCIAS DISTÓPICAS NO BRASIL: A FANTASIA COMO POSSIBILIDADE DE LIDAR COM O PESADELO NA LITERATURA NACIONAL
}

\author{
DYSTOPIAN TENDENCIES IN BRAZIL: \\ FANTASY AS A POSSIBILITY FOR DEALING WITH \\ NIGHTMARE IN BRAZILIAN LITERATURE
}

\author{
Ânderson Martins Pereira \\ Universidade Federal do Rio Grande do Sul \\ Porto Alegre, RS - Brasil \\ ORCID 0000-0003-2667-8891
}

\begin{abstract}
Resumo
O presente artigo busca discutir as especificidades da distopia brasileira, questionando acerca das singularidades na formação de sociedades atrozes e do uso do elemento fantástico para a elaboração e o desenlace destas narrativas em âmbito nacional. Para tal, este trabalho analisa os romances Dorri (2009), de Rafael Silva; Supernova: O encantador de flechas (2015), de Renan Carvalho; e Sombras de Reis Barbudos (1972), de José J. Veiga. Na análise, utiliza-se das contribuiçóes de Causo (2003), Marks de Marques (2014), Matangrano (2013; 2014) e Suvin (1972). Este estudo justifica-se por contribuir com as pesquisas acerca da literatura nacional e acerca do gênero distopia, as quais têm se destacado nas últimas décadas e têm tornado disponíveis novas ferramentas para a (re)leitura de tais textos.
\end{abstract}

Palavras-chave: distopia; fantástico no Brasil; ficção científica.

\section{Abstract}

This paper seeks to discuss the specificities of the dystopian genre in Brazil, analysing its singularities in the formation of dreadful societies and the use of fantastic elements in the elaboration and denouement of these narratives in the Brazilian context. For such purpose, this paper examines the novels: Dorri (2009) by Rafael Silva, Supernova: $O$ encantador de flechas (2015) by Renan Carvalho and Sombras de Reis Barbudos (1972) by José J. Veiga. The analysis is informed by contributions made

\section{Resumen}

Este artículo tiene como objetivo discutir las especificidades del género distópico en Brasil, preguntándose sobre las singularidades en la formación de las sociedades atroces y el uso del elemento fantástico para el desarrollo y el resultado de estas narrativas en el ámbito brasileńo. Con este fin, este trabajo analiza las novelas: Dorri (2009) de Rafael Silva, Supernova: O encantador de flechas (2015) de Renan Carvalho e Sombras de Reis Barbudos (1972) de José J. Veiga. En el análisis, se apela a las 
by Causo (2003), Marks de Marques (2014), Matangrano (2013; 2014) and Suvin (1972). This paper aims to contribute to the study of Brazilian literature and the dystopian genre, which has become especially relevant in recent decades and has provided a new framework for (re)reading such texts.

Keywords: dystopia; fantastic in Brazil; science fiction. contribuciones de Causo (2003), Marks Marques (2014), Matangrano (2013; 2014) y Suvin (1972). Este estudio se justifica por su contribución a las investigaciones sobre la literatura brasileńa y sobre el género distopía, las que se han destacado en las últimas décadas y han disponibilizado nuevas herramientas para la (re)lectura de estos textos.

Palabras clave: distopía; fantástico en Brasil; ciencia ficción.

O termo distopia foi utilizado pela primeira vez pelo filósofo John Stuart Mill em uma de suas falas no parlamento inglês no ano de 1868; o conceito, porém, só ganhou certo destaque no século XX. O conceito hoje representa um gênero essencialmente arraigado na sociedade, e dentre suas características mais marcantes estão a discussão de valores éticos ou morais e a denúncia de suas possíveis deturpaçôes. Para este efeito, as distopias criam uma sociedade atroz, em que os indivíduos que ali coexistem carecem de direitos básicos; e, no universo da obra ficcional, estas prerrogativas são consideradas essenciais para o que se entende por condição humana.

Vários textos teóricos têm buscado estabelecer padróes e lidar com as manifestaçóes propostas pelo gênero desde seu surgimento. Tal origem, segundo Gregory Claeys (2010:110), estaria localizada em meados de 1756 com a publicação da obra Vindication of Natural Society, de Edmund Burke. Desde entâo, reflexôes acerca de valores morais e éticos têm sido debatidas e atualizadas nestes textos e, por conseguinte, pelas teorias que buscam dar conta de tais narrativas. Existe uma tendência notável da distopia de possuir padróes temporais, a qual se encontra no fato de tais textos refletirem as sociedades das quais são produto. Neste sentido, em um mundo dito globalizado, pode-se inferir que é esperado que a distopia seja reformatada mais pelo tempo do que pelo espaço. Pode-se observar que, na contemporaneidade, as fronteiras espaciais têm sido obscurecidas; porém, as mudanças tecnológicas constantes têm feito do tempo um fator de mudança social mais premente do que o espaço. Contudo, 
isso não ocorre no Brasil, pois a literatura decorrente deste espaço possui formas alternativas de construção de narrativas distópicas que destoam das demais tendências temporais. Assim, este trabalho busca avaliar algumas semelhanças e dissonâncias da distopia brasileira frente às tendências globais do gênero, principalmente no que tange ao incomum uso da fantasia, para a representação de tais sociedades.

Entretanto, antes de observar as especificidades do Brasil, é necessário um olhar mais amplo para o gênero. Chris Ferns (1999) vincula a distopia à utopia, ainda que ambas possuam construçōes estéticas distintas. Para o autor, o ideal pessimista, marca da distopia, aparece após as decepçôes com promessas sociais que não foram concretizadas. É necessário, portanto, entender o enquadramento histórico de ambos os gêneros. As primeiras utopias tiveram em seu contexto de criação um mundo em que os avanços tecnológicos eram crescentes. Com o desenvolvimento da navegaçáo, a ideia de encontrar sociedades diferentes permeava o imaginário do século XVI, e a possibilidade de encontrar uma sociedade mais evoluída inspirou A Utopia (1516), de More. Desde entáo, as promessas tecnológicas foram colaborando para uma visão mais positivista de história humana. Esse contexto possibilitou a abertura da sociedade às utopias, as quais problematizavam a sociedade do leitor por meio de realidades idealizadas. A exemplo disso, a obra Nova Atlântida, de Francis Bacon, publicada originalmente em 1627, se utilizou largamente da tecnologia para criação e manutenção da sua sociedade utópica. Os usos da tecnologia implementam as colheitas, melhoram a saúde e o bem-estar, mas ferem alguns conceitos que atualmente são considerados parte da ética humana. Tanto a utopia como a distopia são termos estritamente arraigados na sociedade; o que enquadra tais obras a essas definiçóes é o conceito de pesadelo ou sonho estabelecido pela sociedade que os discrimina. Pode-se dizer, por exemplo, que um leitor contemporâneo talvez tivesse dificuldade em considerar alguns textos antigos como utópicos.

Várias crises sociais causaram o descrédito da utopia e posterior ascensão da distopia; porém, após o mundo passar pelo Holocausto e pela Segunda Guerra Mundial, a tecnologia, outrora base de muitos sonhos, torna-se arma de controle e massacre, criando um cenário ainda mais favorável à proliferação do gênero. Booker 
(1994), em seu livro Dystopian Literature: A Theory and Research Guide, pontua não apenas os eventos sociais como facilitadores da proliferação do gênero, mas também as descobertas científicas, como a publicação do livro $A$ origem das espécies de Charles Darwin (1859), que ressignificou a existência humana, questionando a fé cristá e a gerência do destino da humanidade, a partir de um ser superior. $\mathrm{Na}$ obra de Darwin, a evolução não é vista mais como desenvolvimento constante, mas como processo aleatório, elemento que demonstrara a fragilidade da espécie humana frente ao universo.

Outro fator elencado por Booker (1994) como mudança de paradigma acerca da concepção positivista de história e de sociedade é a publicação em 1850 da Segunda Lei da Termodinâmica pelo físico Rudolf Clausius, que desenvolve a ideia de entropia e demonstra que quanto mais o sistema evolui, mais energia é consumida, até que, por fim, entra em colapso. Dessa forma, a história humana estaria fadada ao caos e ao eventual aniquilamento. Neste cenário, a utopia perdeu espaço e narrativas pessimistas de futuro tiveram fácil aceitação do público da época.

A partir do exposto, é possível observar que a tecnologia é importante na criação do gênero distopia, e é um item que está intrinsecamente ligado ao enredo de várias histórias do gênero. A distopia e a ficção científica estão muito imbricadas, e poucos são os romances distópicos que não se utilizam dos princípios deste último gênero na composição de suas sociedades. Darko Suvin (1972, p. 376), um dos pioneiros a teorizar sobre ficção científica, acredita que a condição sinequa non para sua existência é a ocorrência de um Novum. Este seria, basicamente, a ferramenta tecnológica que o personagem possui para desenrolar a ação; porém, esta deve possuir verossimilhança não frente à ciência da sociedade atual, mas à do universo narrado. No mesmo sentido, Adam Roberts (2002) acredita que, para a obtenção de tal condição, é necessário que a narrativa reinscreva características do nosso mundo no mundo inventado. Dessa forma, o mundo fictício deveria dosar novas características com noçôes e elementos já conhecidos. É possível considerar a afinidade entre a distopia e a ficção científica como natural, visto que elementos como a verossimilhança e o uso das tecnologias na criação de novos mundos são comuns a ambos os gêneros. 
Contudo, a distopia no Brasil pouco se vale da ficção científica, mas vem majoritariamente recorrendo à fantasia na criação de suas sociedades alternativas. Diferentemente da ficção científica, a fantasia, segundo Tzvetan Todorov (2012, p. 32), não necessita de uma explicação que faça sentido dentro de parâmetros existentes no mundo real. Ela trata da apresentação de elementos ou lugares que existem apenas dentro do espaço da obra, sendo os parâmetros para tal ocorrência desconhecidos ou irrelevantes. Contudo, essa característica é entendida pelo leitor, que concebe o fantástico a partir da hipótese de sua existência, e não de sua explicação.

O uso da fantasia para obras distópicas é atípico, pois o objetivo de tais textos é demonstrar a possibilidade de realização de tais sistemas no mundo atual. Isso não quer dizer que as distopias se furtem da utilização do extraordinário, mas em geral o elemento fantástico dificultaria a plausibilidade de tais sistemas sociais. A razoabilidade da ocorrência de tais narrativas é vista por Phillip E. Wegner (2002) em seu livro intitulado Imaginary Communities: Utopia, the Nation, and the Spatial Histories of Modernity; porém, ele alia tal similaridade ao viés educativo dos textos, que chama utópicos, mas que correspondem tanto ao gênero utopia como ao gênero distopia.

[...] [i] $\mathrm{n}$ the narrative utopia, the presentation of an "ideal world" operates as a kind of lure, a play on deep desires, both immediately historical and otherwise, to draw its readers in and thereby enable the form's educational machinery to go to work - a machinery that enables its readers to perceive the world they occupy in a new way, providing them with some of the skills and dispositions necessary to inhabit an emerging social, political, and cultural environment ${ }^{1}$ (WEGNER, 2002, p.2)

1 “[...] na narrativa utópica, a apresentação de um "mundo ideal” funciona como uma espécie de isca, uma brincadeira com desejos profundos, ambos imediatamente históricos e de outra maneira, para delinear seus leitores e, assim, permitir que a máquina educacional da forma funcione. - uma máquina que permite a seus leitores perceber o mundo que ocupam de uma nova maneira, proporcionando-lhes algumas das habilidades e disposiçóes necessárias para habitar um ambiente social, político e cultural emergente" (WEGNER, 2002, p. 2, tradução nossa) 
Na passagem acima, retirada do livro Sobre histórias de Fadas, J.R.R. Tolkien ressalta que a magia do belo reino ou do universo fantástico per se não é um fim ou um início em si mesma, mas que lida diretamente com o desejo. Aproximar o elemento do desejo - conhecido motivador da utopia, considerada principalmente como realidade de sonho por Wegner (2002) - de narrativas que se inscrevem no pesadelo é, portanto, possível, já que elas lidam inversamente com o desejo. Segundo Michel Foucault (2004, p. 10) no livro A ordem do discurso, "o desejo é, também, aquilo que é o objeto do desejo"; pode-se pensar, então, que a impossibilidade de realização do desejo ou o medo da realizaçáo de algo externo e contrário a ele deem vazão a realidades fantásticas de pesadelo. É este o processo que será analisado nas distopias nacionais.

Para análise da incorrência do elemento fantástico na literatura nacional, este trabalho busca versar sobre três romances. $\mathrm{O}$ primeiro, que se acredita ser o texto inaugural do gênero distopia no Brasil, é publicado por José J. Veiga em 1972, e se intitula Sombras de reis barbudos. O livro foi escrito no auge de aceitaçáo da ditatura militar no Brasil, em um período em que os cidadáos apoiavam o chamado "milagre econômico" de 1970, e foi neste período que o governo mais utilizou seu poder para censurar os meios de comunicação, torturar e exilar os inimigos do Estado. A obra retrata a vida de uma cidade que vê seus direitos se esvaírem aos poucos, a partir da implementação de um novo regime ditatorial. Bruno Anselmi Matangrano (2014) elenca este romance como um dos textos fundamentais para a consolidação do fantástico nacional; e é somente através deste elemento que mudanças substanciais ocorrem na vida desta comunidade em um curto espaço de tempo.

As outras obras escolhidas são distopias contemporâneas. A primeira é Dorri (2009), escrita por Rafael Silva, e a segunda é $O$ encantador de flechas (2014), de Renan Carvalho, primeiro volume da trilogia Supernova. Ambas as obras correspondem a uma tendência mundial de ascensão do gênero distopia. As correntes contemporâneas que auxiliam este ressurgimento seráo mais bem exploradas à frente, bem como a adaptação nacional de tais tendências.

Como dito, o fantástico tem uma relação ímpar com as distopias nacionais, e isso se deve à afinidade singular que este elemento 
tem com a literatura brasileira, pois opera uma área considerável neste espaço em vista de outros gêneros literários. Tal característica é vista por Bruno Anselmi Matangrano (2013, p. 49) como decorrente dos próprios processos de aquisição dos conceitos de fantástico e da literatura nacional, as se deram em conjunto. No artigo "O Fantástico no Brasil: As Origens", o autor pontua que, enquanto alguns sistemas literários observaram o gênero fantasia receber contornos próximos aos reconhecidos hoje, o que se deu no fim do século XVIII e começo do XIX, a literatura brasileira consolidou-se quase em conjunto ao elemento fantástico, visto que tal consistência só ocorreu no século XIX. Tendo em vista essa relação ancestral, ainda que a literatura brasileira contemporânea tenda mais ao realismo, náo é surpreendente o fato de a distopia nacional remontar esta ponte com o fantástico na criação de suas narrativas.

A conexão entre distopia e fantasia na literatura nacional pode ser percebida desde Sombras de reis barbudos (1972). Naturalmente, o sistema literário brasileiro possui várias obras com elementos distópicos anteriores a este romance. Todavia, este é considerado o primordial por adequar-se a todas as características do gênero, tendo em vista o referencial teórico aqui utilizado. Neste romance, o elemento tecnologia não é apenas evitado, mas em certa medida satirizado, já que os grandes problemas desta sociedade distópica principiam com a vinda de uma fábrica que prometia grandes avanços neste campo para a regiáo. $\mathrm{O}$ primeiro dono da fábrica, tio do narrador, sonha constantemente com os benefícios deste empreendimento para a sociedade, o que de certa forma assemelha-se ao espírito utópico relegado à tecnologia. Contudo, após ser destituído do cargo, a empresa começa a ditar várias regras para a população, a construir muros e a eleger fiscais para controlar as pessoas. A história demonstra como o medo é lido e vivenciado sobre o prisma da visão de um menino de apenas dez anos.

Dentre os componentes fantásticos da obra, pode-se destacar a aparição de vários urubus que deixam de ser um problema e acabam sendo domesticados pela população, e o próprio final aberto do romance. Em uma conversa, se menciona o voo das pessoas como frequente. Chamun, personagem dono de uma loja, ao ser indagado sobre a veracidade desse fato, comenta a situação como se fosse parte de uma rotina aceitável. Os humanos não voavam no universo da 
narrativa; porém, o personagem explica o evento como parte de uma alucinaçáo coletiva que não seria uma doença, e sim uma medida profilática contra a loucura.

E quando vi, o tal professor abotoou o paletó e saiu depressa. Eu estava de costas para aporta, olhando para Seu Chamun, interessado na reação dele, e tive a impressão de que a sombra do professor se elevava no espaço. Não me interessei em tirar a limpo porque já estou cansado de ver gente voando. (VEIGA, 1972, p. 136)

Devido à impossibilidade de fugir do regime, ou da "festa dos reis barbudos", como mencionado na obra, os personagens alçam voo, mas acabam tendo que voltar ao solo para lidar com essa dura realidade. Dessa forma, a fantasia na obra opera na construção da realidade distópica, como na chegada dos urubus ou mudanças repentinas que ocorrem e são facilmente assimiladas, mas é principalmente na figuração do sentimento utópico que ela será indispensável. A fantasia é o único meio de fuga dentro deste sistema. Ela se torna o medicamento contra a loucura, fazendo com que os indivíduos subsistam até que dias melhores cheguem. Pode-se dizer que o elemento fantástico é a única possibilidade de futuro utópico, já que a realidade demonstra somente o caos.

Neste contexto, a obra de Veiga não destoa de outras narrativas produzidas sob ditaduras latino-americanas. Como no caso de Sombras de reis barbudos, outros autores se utilizaram do realismo fantástico como reforço das palavras contrárias aos regimes ditatoriais. Angel Flores (1995), em um ensaio nominado Magical Realism in Spanish American Fiction, demonstra que a confluência de tecnologia com a superstição, comum a esses países, é essencial para a criação destas narrativas, as quais buscam no fantástico uma ferramenta para lidar com a realidade e/ou escapar de uma situação incômoda.

Infelizmente, não foram encontradas outras narrativas passíveis de serem consideradas distopias no mesmo intervalo de tempo ou em um momento mais próximo à narrativa de Veiga; assim, as outras obras aqui analisadas são contemporâneas e representam um outro período do gênero. As distopias contemporâneas, como se verá, não possuem como foco a denúncia da sociedade, mas a essência do 
humano frente à tecnologia. Eduardo Marks de Marques (2014), neste cenário, ao examinar as distopias contemporâneas, acredita que há uma evolução em âmbito temático do gênero.

[g]ostaria de propor que a tendência encontrada nos romances distópicos, principalmente, publicados a partir da década de 1990 rejeitam a mera leitura política proposta pelas distopias clássicas e propóem a discussão dos ideais filosóficos e sociais do transumanismo e pós-humanismo a partir da centralidade do corpo transumano como resultante do modelo distópico. Os romances que compóem o que chamo de terceira virada distópica são aqueles em que o centro do ideal utópico náo está em uma forma centralizada de controle social, político e/ou cultural sobre os indivíduos, mas, sim, na relaçáo entre o corpo orgânico (falho, defeituoso e imperfeito) e as promessas tecnológicas advindas do modelo capitalista pós-moderno em melhorá-lo e aperfeiçoá-lo e que, ao fazê-lo, negam a essência orgânica do ser humano. (MARKS DE MARQUES, 2014, p. 10)

Ao observar essa nova leva de distopias, o autor cunha o termo terceira virada distópica, e as obras pertencentes a este momento focariam náo na discussão do humano representado no social, mas na própria essência de humanidade desafiada por correntes filosóficas como o pós-humanismo e o transumanismo. Neste viés, as duas distopias brasileiras contemporâneas, aqui analisadas, transgridem os padróes globais do gênero, já que ambas as obras não se encaixam completamente nessa definição. A primeira, apesar de trazer uma problemática de evolução, não o faz sob um ponto de vista filosófico-tecnológico, mas sim de uma maneira que se assemelha ao fantástico-mitológico. A segunda se localiza em um universo mágico que aparenta ter grandes traços contemporâneos e não discute tais problemas. Ainda assim, a ideia de evolução do gênero para um novo momento demonstra o compromisso crescente do mesmo com questóes tecnológicas; e, neste sentido, as distopias contemporâneas são majoritariamente textos de ficção científica. Entretanto, o Brasil, como se tem observado, vem desafiando essa tendência, e isso náo ocorre de maneira distinta na contemporaneidade. 
Neste sentido, Dorri, obra distópica publicada primeiramente em 2009, busca uma evolução da espécie humana, mas essa evoluçâo não é exatamente transumana, já que o papel da tecnologia não figura como central neste processo. Ainda que conceitos como nanocirurgia permeiem a obra, existe uma mescla entre os elementos de ficção científica e os de fantasia; todavia, ambos os elementos são indispensáveis ao romance.

$\mathrm{O}$ que você acha? Desde que o primeiro hominídeo empunhou a primeira clava nossa real natureza foi revelada: o poder é o fim último para todo homem. Tudo se desenvolveu neste sentido, filho. Assim caminhou a humanidade, entre passos tortos e brutos. A questão não é mais a de como evitar - na realidade nunca foi realmente. Somente os mais ingênuos para acreditar - A questáo é: como superar. E náo digo isto num sentido semelhante ao anterior. O que quero dizer é que o mundo moderno do qual eu sou apenas a consumação inevitável - seleciona aqueles que abraçam a verdadeira natureza do homem. $\mathrm{O}$ capitalismo permitiu. (SILVA, 2015 [2009], p. 394)

O excerto extraído da obra demonstra uma certa conformidade da obra com os padróes de ficção científica. É possível inferir também "como superar" uma ideia de evolução da espécie que é largamente problematizada na obra. A questâo do capitalismo proposta pelo autor brasileiro combina com a ideia de terceira virada distópica proposta por Marks de Marques (2014), o qual considera o modelo econômico como fator fundamental para a transformação do corpo em produto, e a falha deste de se adaptar às novas necessidades perante tal sistema. Contudo, a obra se vale de uma evolução que se mistura em muito à fantasia, a qual, de maneira geral, está em muito arraigada na mitologia de várias culturas.

O azul-claro demoníaco voltou a incendiar seus olhos. O cenho tornou-se carregado enquanto levantava o queixo para fitar novamente Morgan - Morgan? - Quase podia sentir asas brotando de suas costas. Não as de um anjo, mas de um demônio, certamente. Quase podia sentir chifres e uma cauda. Porque neste momento ele não era mais nada, nem Shal'eir, muito menos humano. Era 
definitivamente um demônio. E seu coração demandava a consumação da vingança; demandava... o sacrifício por sangue. (SILVA, 2015 [2009], p. 398)

No excerto acima, pode-se perceber a descrição destes seres evoluídos pelo autor; tal evolução traz consigo uma aura fantástica, que lhes garante habilidades supremas frente aos demais. Para conseguir tal efeito, Rafael Silva utiliza-se de elementos mitológicos - na passagem acima, é possível inferir referências cristâs. Os componentes religiosos atrelados ao fantástico são enfatizados por Roberto da Silva Causo (2003) em seu livro Ficçáo científica, fantasia e horror no Brasil: 1875 a 1950.

Também temos, como forte tempero, muitas tradições religiosas e suas expressóes sincréticas, no caldeirão brasileiro de religiosidade e misticismo. A pajelança nativo-brasileira, o fervoroso catolicismo, os cultos afro, e várias seitas protestantes mais recentemente importadas, as tradiçóes xintoístas e budista que vieram com os colonos japoneses no começo do século XX, e o difundido espiritismo, doutrina religiosa-filosófica nascida na França no século XIX, mas que dizem alguns, encontrou o seu verdadeiro lar no Brasil. (CAUSO, 2003, p. 102-103)

Diante do exposto, fica fácil estabelecer a relação dos seres evoluídos e de elementos míticos. Estes elementos fantásticos são utilizados muitas vezes por dividirem um pré-texto com o leitor e ajudarem a construir significados, dar forma a tais seres; a descrição de tais seres também contribuem para um descomprometimento com uma explicaçáo estritamente científica. Todavia, na obra supracitada, Sombras de reis barbudos, o imaginário e o simbolismo dos urubus são vários e auxiliam a compor uma aura místico-fantástica na história.

Neste sentido, a obra $O$ encantador de flechas é singular. Como visto em vários textos distópicos, existe uma necessidade de explicação dos elementos fenomenais por uma nuance científica; porém, esta obra busca tal elucidação em componentes mitológicos. Para tal, Renan Carvalho introduz à obra um prólogo, no qual conta ao leitor as crenças do povo de Acigam. Tal estrutura do panteão de deidades não apenas estará presente na organização da vida do 
povo desta cidade isolada, mas também ajuda o leitor a encontrar explicaçóes e embasamento para o fantástico explorado no decorrer da narrativa.

\begin{abstract}
Depois que eu insisti bastante com as perguntas, ele me confirmou que, em outros lugares, esses "magos" existem mesmo, mas em Acigam a prática dessa curiosa ciência é proibida. [...] Depois de descobrir a verdade passei a desconfiar de que algumas coisas ensinadas em Acigam não passam de enganação para controlar melhor os jovens, para manter os questionamentos longe de nossas mentes. Mas tudo bem, tenho sorte de conhecer alguém capaz de me mostrar outras visóes. (CARVALHO, 2015, p. 16)
\end{abstract}

Na passagem acima, Leran, narrador do romance, demonstra como é que, a partir do estudo da magia, descobrira a real ciência de seu universo; tal ciência encontrará fundamento não em leis físicas, mas sim nos componentes míticos de criação do mundo feitos pelos Deuses do universo criado por Renan Carvalho. Esta narrativa inicial será necessária para que o protagonista entenda a relação dos seis elementos existentes em tal universo e para que a sua relação com a magia possua uma certa lógica e seja mais crível ao leitor.

Nas duas obras contemporâneas aqui examinadas, o uso da fantasia é, também, explicativo, já que alguns elementos da evolução humana proposta por Dorri são possíveis apenas a partir de uma aproximação com o fantástico-mítico. Pode-se aventar a possibilidade de que o fantástico, antes utilizado por Veiga (1982) como única possibilidade de escape, contemporaneamente começa a possuir um papel atrelado à verossimilidade da narrativa.

O componente fantástico operaria então as vias de ficção científica nas distopias brasileiras; porém, alguns outros elementos gerais do gênero permaneceriam similares. Tal leitura é possível quando pensamos nos elementos de segunda virada propostos por Gregory Claeys (2010), e observamos este mesmo padrão de denúncia ao social em Sombra de reis barbudos. As questôes filosóficas relacionadas à essência humana frente a movimentos filosóficos, como o pós-humanismo e o transumanismo, propostas por Marks de Marques (2014), não são totalmente observadas nas distopias contemporâneas. Contu- 
do, uma tentativa real de melhoramento da raça humana em Dorri e a questáo do capitalismo na questáo do corpo podem ser observadas em $O$ encantador de flechas.

Agora tudo faz sentido. Os comerciantes se reuniam para falar sobre os problemas da cidade e nos intervalos, trocavam conhecimento sobre o controle de energias, uma vez que a fonte desse saber náo podia mais ser acessada. Isso confirma minha teoria: $\mathrm{O}$ motivo do conflito atual é muito mais financeiro e político do que algo relacionado ao controle. Os magos estáo envolvidos pela simples coincidência de que essa prática é mais comum na classe comerciante. Hoje, o controle é a única arma que eles têm contra o governo. (CARVALHO, 2015, p. 40)

Pode-se observar na passagem acima que apenas uma classe social específica de Acigam tem acesso à magia. Os comerciantes, antes de a cidade ser isolada, possuíam mais acesso à informação devido às suas viagens, e fora nessa classe que o conhecimento sobre o controle das energias perseverou. Se pensarmos na magia como um elemento que transcende as limitaçóes do corpo humano e que tal elemento está intrinsecamente ligado à questão social, podemos estabelecer muitas conexôes com a teoria de Marks de Marques (2014), ainda que não se possa aventar a nítida existência de traços transumanistas na obra.

Uma das características largamente utilizadas nas narrativas distópicas, em geral, é a utilização do futuro para hospedar uma sociedade de pesadelo, e tal medida reside na necessidade de denúncia do presente e, eventual, pessimismo quanto ao futuro. Majoritariamente os textos deste gênero não finalizam com uma promessa esperançosa, mas sim com a aceitação resignada de que o futuro é caos. Todavia, as três obras aqui analisadas inscrevem suas sociedades no presente de sua publicação, e tal característica demonstra um olhar mais otimista quanto ao futuro das questóes abordadas dentro das histórias. Neste âmbito, o elemento fantástico é de extrema relevância para a inscrição dessa característica nas narrativas aqui analisadas. Como já observado, o fantástico em Sombras de reis barbudos (1972) é a chave para a esperança da população; pode-se inferir, assim, que existe uma possibilidade de que dias melhores apareçam e a distopia se desfaça. 
Na obra Dorri (2009), há um final também aberto; nele a personagem Lenna se compromete a não seguir os padrôes de seu criador, decidindo ser apenas humana. O livro encerra com a frase: "A humanidade não estava totalmente perdida afinal"; nela, é importante destacar a palavra "totalmente", já que a maioria das distopias aponta uma visão pessimista para o futuro da própria narrativa. Assim, a obra de Rafael Silva, ainda que reconheça um potencial destrutivo de futuro, possibilita a existência da esperança para com o mesmo.

\section{Considerações finais}

Como se pôde observar, a relação da literatura brasileira com o fantástico é sui generis, já que ambos têm uma história de certa forma mesclada. Neste sentido, o componente fantástico permite às narrativas distópicas nacionais uma fluidez maior, já que não necessitam atar-se tão firmemente à plausibilidade; tal premissa pode ser observada na possibilidade de escape através do voo para além dos muros na obra de José J.Veiga (1983[1972]), do uso da magia como forma de lutar contra o governo na narrativa de Renan Carvalho (2015), ou na criação de corpos pós-humanos que são perpassados por um mítico mágico, os quais são causa e livramento do cenário distópico da obra de Rafael Silva (2015 [2009]).

Tentou-se demonstrar, através da leitura das três obras, que o "não lugar" distópico é perpassado pelo componente fantástico, o que se sucede sobremaneira nas três narrativas aqui analisadas. É importante salientar, também, que o número de obras aqui revistas é expressivo, visto que as narrativas que podem receber a alcunha de distopia no Brasil são poucas. Dessa forma, é possível inferir que tal fenômeno faz parte de uma característica das narrativas do gênero produzidas no Brasil.

Por fim, ainda que não tenham sido encontrados estudos prévios acerca do gênero distopia em âmbito nacional, salienta-se a relevância desde estudo tanto para fins qualitativos da literatura brasileira, como para estudos dentro da distopia e de sua relação com a ficção científica e com o fantástico. 


\section{Referências bibliográficas}

BOOKER, M. Keith. Dystopian Literature: A Theory and Research Guide. Westport: Greenwood, 1994.

CARVALHO, Renan. Supernova: O encantador de flechas. 2.ed. Ribeirão Preto: Novo Conceito Editora LPL, 2015.

CAUSO, Roberto da Silva. Fiç̧ão cientifica, fantasia e horror no Brasil: 1875 a 1950. Belo Horizonte: UFMG, 2003.

CLAEYS, Gregory. The Origins of Dystopia: Wells, Huxley and Orwell. In:___ (ed.). The Cambridge Companion to Utopian Literature. Cambridge: Cambridge University Press, 2010.

DARWIN, Charles. A origem das espécies através da selecção natural, ou a preservação das raças favorecidas na luta pela sobrevivência. Traduçáo de: Ana Afonso. Leça da Palmeira: Planeta vivo, 2009 [1859].

FERNS, Chris. Narrating Utopia: Ideology, Gender, Form in Utopian Literature. Liverpool: Liverpool University Press, 1999.

FLORES, Angel. Magical Realism in Spanish American Fiction. In: ZAMORA, Lois Parker; FARIS, Wendy B. Magical Realism: Theory, History, Community. Durham: Duke University P, 1995.

ROBERTS, Adam. Science fiction: The new critical idiom. London: Routledge, 2002.

MATANGRANO, Bruno Anselmi. O Fantástico no Brasil: As Origens. Revista Bang! - A sua revista de fantasia. Rio de Janeiro, v. FC e horror, n. 0, 2013, p. 49-55.

. O Fantástico no Brasil - Parte II: A Consolidação do Gênero. Revista Bang! Brasil - A sua revista de Fantasia. Rio de Janeiro, v. FC e Horror, n. 1, 2014, p. 49-56.

MARKS DE MARQUES, Eduardo. Da centralidade política à centralidade do corpo transumano: movimentos da terceira virada distópica na literatura. Anuário de Literatura, Florianópolis, v. 19, n. 1, p. 1029, 2014.

SILVA, Rafael. Dorri. 2.ed. São Paulo: Chiado, 2015 [2009].

SUVIN, Darko. On the Poetics of the Science Fiction Genre. National Council of Teachers of English Stable, Urbana, v. 34, n. 3, 1972, p. 372-382.

TODOROV, Tzvetan. Introdução à literatura fantástica. Tradução de Maria Clara Correa Castello. 4 ed. Manaus: Editora Perspectiva, 2012. 
TOLKIEN, J.R.R. Sobre histórias de Fadas. Tradução de Ronald Eduard Kyrmse. São Paulo: Conrad, 2006.

VEIGA, José J. Sombras de reis barbudos. São Paulo: DIFEL, 1983[1972].

WEGNER, Philip E. Imaginary Communities: Utopia, the Nation, and the Spatial Histories of Modernity. University of California Press: London, 2002.

Ânderson Martins Pereira é graduado em Letras (Português/Inglês) e especializado em Linguagem e Docência pela Universidade Federal do Pampa (UNIPAMPA). É Mestre em Literatura Comparada na Universidade Federal de Pelotas (UFPel), período no qual foi bolsista Capes. Atualmente é Doutorando em Estudos Literários na Universidade Federal do Rio Grande do Sul (UFRGS), com ênfase na linha Sociedade, (inter)textos literários e tradução nas Literaturas Estrangeiras Modernas. Atua principalmente sob os temas: Utopia, Distopia, transumanidade, pós-modernidade e pós-humanidade. E-mail: andersonmartinsp@gmail.com

Recebido em: 16/01/2018

Aceito em: 15/07/2018 